\title{
Rehabilitation and quality of life in diabetic patients after successful pancreas-kidney transplantation
}

\author{
Ø. H. Bentdal ${ }^{1}$, P. Fauchald ${ }^{2}$, I. B. Brekke ${ }^{1}$, H. Holdaas ${ }^{2}$ and A. Hartmann ${ }^{2}$ \\ ${ }^{1}$ Department of Surgery B and ${ }^{2}$ Department of Medicine B, Rikshospitalet, The National Hospital, University of Oslo, Norway
}

Summary. Twenty-seven Type I diabetic patients in endstage renal failure were followed after combined pancreaskidney transplantation. All patients received duct-occluded segmental pancreas grafts. Clinical progression of extrarenal diabetic complications was studied in 11 patients with longterm functioning pancreatic and renal transplants (Group 1), and in 16 patients who had lost pancreatic graft function, but retained renal graft function (Group 2). Pretransplant, extrarenal diabetic complications were equally distributed in the two groups. In the follow-up period, however, the progress of these complications was less severe in patients with functioning pancreatic transplants. No differences were found between the groups concerning rehabilitation, working capacity, need of help or hospital admittance. It is suggested that pancreas transplantation performed in an earlier stage of diabetes before serious complications have developed, would probably improve rehabilitation and quality of life in these patients.

Key words: Pancreas transplantation - Diabetes - Organ complications - Rehabilitation - Quality of life

\section{Introduction}

Several studies of diabetic patients in end-stage renal failure (ESRF) have documented that kidney transplant patients have higher employment and quality of life including better perceived health status than patients on dialysis (Johnson et al 1982; Evans et al 1985; Kutner et al 1986).

So far only a few studies on quality of life in patients after combined pancreas-kidney transplants have been published (Nakache et al 1989). This study showed that patients with combined grafts had improved quality of life with a less resticted life-style than patients with kidney transplants alone.

The aim of this investigation was to compare rehabilitation and quality of life in patients with functioning pancreaskidney transplant with patients who had functioning kidney graft, but non-functioning pancreas graft.

\section{Patients and methods}

Thirty-nine Type I diabetic patients in ESRF received combined pancreaskidney transplants between June 1983 and January 1987. Patient age was 24-53 (mean 39) years and duration of diabetes was 7-37 (mean 24) years. Advanced diabetic complications were present in several recipients before transplantation; 10 were blind, 2 had a history of myocardial infarction, 4 had symptomatic coronary heart disease and 6 had experienced cerebrovascular insults.

Duct-occluded segmental pancreatic grafts were used in all patients and $40 \%$ of the transplantations were performed in predialytic recipients.

At follow-up in May 1990, 29 patients were alive, but 2 of the patients had lost both grafts. Observation time was 40-84 (mean 62) months (range 40-84). Group 1 consisted of 11 patients with functioning pancreas and kidney transplants $>3$ years. Group 2 consisted of 16 patients who had lost pancreas, but had functioning kidney transplant $>3$ years. Diabetic complications were equally distributed in the two groups before transplantation.

At follow-up the recipients were assessed by objective means and by questioning by a medically qualified interviewer. Evaluation of rehabilitation, physical and social ability was performed. Assessment of emotional and psychological well-being was not included in this study.

\section{Results}

Diabetic complications which had developed after transplantation and were observed at follow-up were significantly higher in Group 2 compared to Group 1. In 
Group 1 only one patient had below knee amputation while 2 patients in group 2 had amputations. In addition, two patients suffered myocardial infarctions, one developed symtomatic coronary heart disease and three had one or more cerebrovascular insults in Group 2.

The need of help was higher in Group 2 compared to Group $1,25 \%$ and $18 \%$ respectively (no statistical significant difference). All patients were living at home except one patient in Group 1 who had hemiplegia before transplantation. Rehabilitation was remarkably good in both Groups in spite of advanced diabetic complications. Marital status was unchanged in all patients in group 2 while two patients in Group 1 were divorced. The ability to work was 64 and $62 \%$ in Group 1 and 2 respectively (Table 1).

Table 1. Working capacity in recipients of combined pancreaskidney transplants

\begin{tabular}{lcc}
\hline $\begin{array}{l}\text { Working } \\
\text { capacity }\end{array}$ & $\begin{array}{l}\text { Both grafts } \\
\text { functioning }\end{array}$ & $\begin{array}{l}\text { Only kidney } \\
\text { functioning }\end{array}$ \\
\hline Full-time work & $4 / 11$ & $5 / 16$ \\
Part-time work & $3 / 11$ & $5 / 16$ \\
Unable to work & $4 / 11$ & $6 / 16$ \\
\hline
\end{tabular}

\section{Discussion}

In this retrospective study there was no difference between the two groups concerning rehabilitation and ability to work. It is probable that assessment of emotional and psychological well-being would have demonstrated important differences between the two groups.

As mentioned above, one study reported better quality of life in patients after combined pancreas-kidney transplantation compared to kidney transplantation alone (Nakache et al 1989). The control group in the study was heterogenous; some patients received combined grafts with immediate failure of pancreas graft while others received living-donor or cadaveric transplants only.

However, in our study extrarenal diabetic complications advancing to amputation or myocardial infarction were significantly reduced in patients with functioning pancreas and renal grafts as compared with patients with functioning renal graft only. This is in accordance with recent studies (Abendroth et al.1990; Brekke et al. 1990) reporting improved survival in patients with combined grafts.

Even though several studies have failed to demonstrate reversibility of morphological changes in advanced diabetes, this study indicates that normalization of carbohydrate metabolism is important even in patients with severe renal and extrarenal diabetic complications. Thus, the majority of diabetic patients approaching ESRF should be considered for a combined renal and pancreatic transplantation.

\section{References}

Abendroth D, Illner WD, Landgraf R, Land W (1990) A different clinical course of IDDM patients after simultaneous pancreas and kidney transplantation and kidney grafting alone. Transplant Proc 22:1579

Brekke IB, Holdaas H, Albrechtsen D, Fauchald P, Flatmark A (1990) Combined pancreatic and renal transplantation:improved survival of uremic diabetic patients and renal grafts. Transplant Proc 22:1580

Evans RW, Manninen DL, Garrison LP (1985) The quality of life of patients with end stage renal disease. $N$ Engl $J$ Med 312: 553-559 Johnson JP, Mc Cauley CR, Copley JB (1982) The quality of life of hemodialysis and transplant patients. Kidney Int 22: 286-291

Kutner NG, Brogan D, Kutner MH (1986) End stage renal disease treatment modality and patients' quality of life. Am I Nephrol 6: 396402

Nakache R, Tydén G, Groth CG (1989) Quality of life in diabetic patients after combined pancreas-kidney or kidney transplantation. Diabetes $38: 40-42$

Dr. Ø. Bentdal

Surgical Department B

Rikshospitalet, University of Oslo

0027 Oslo 1, Norway 